\section{Studies on magnetron-sputtered zirconium-silicide coatings deposited on zirconium alloy for the enhancement of their high-temperature oxidation resistance}

Wojciech Starosta, Viera K. Semina, Jerzy Smolik, Lech Waliś, Michal Rydzewski, Bożena Sartowska

\begin{abstract}
Zirconium alloys used widely in nuclear industry as fuel claddings are prone to violent oxidation in water steam atmosphere in the case of loss of coolant accident (LOCA). Accompanying generation of large quantities of heat and explosive gaseous hydrogen may lead to destruction of nuclear core. As the safety of nuclear installations is of primary importance, intensive research works are conducted on the development of so-called accident tolerant fuels much less prone to oxidation. In this paper, the application of external zirconium-silicide coatings deposited by magnetron sputtering is proposed. The preliminary results of their synthesis and studies of air oxidation properties at elevated temperatures are presented.
\end{abstract}

Keywords: accident tolerant fuels $\bullet$ zirconium-silicide coatings $\bullet$ magnetron sputtering

W. Starosta ${ }^{\bowtie}$, L. Waliś, B. Sartowska Institute of Nuclear Chemistry and Technology 16 Dorodna St., 03-195 Warsaw, Poland

E-mail: w.starosta@ichtj.waw.pl

\section{K. Semina}

Flerov Laboratory of Nuclear Reactions

Joint Institute for Nuclear Research

141980 Dubna, Moscow region, Russia

J. Smolik, M. Rydzewski

Institute for Sustainable Technologies

6/10 K. Pułaskiego St., 26-600 Radom, Poland

Received: 25 November 2017

Accepted: 18 September 2018

\section{Introduction}

In accordance with the International Atomic Energy Agency (IAEA) report on nuclear energy status issued at the mid of 2017 year, at the end of 2016, there were 498 nuclear reactors operational in the world, which generated approximately 20\% of the electricity consumed [1]. Most of them were water-cooled reactors utilizing zirconium oxide fuel enclosed in zirconium tubes. Such technology was developed around 50 years ago. Thanks to its continuous improvements in later years is now stable and effective one. This is attributed to very good properties of zirconium alloys such as low absorption of thermal neutron, good enough mechanical properties and resistance to the neutron irradiation and acceptable resistance to the corrosion in water environment at working temperature of the reactor amounting to around $360^{\circ} \mathrm{C}$. However, in the case of the permanent abrupt of main cooling loop (LOCA - loss of coolant accidents), the working conditions change dramatically and severe damages to reactor core could happen. The reason for this is exothermic reaction of zirconium with oxygen; the rate of them accelerates rapidly when temperature grows. Lack of cooling leads to temperature growth of fuel elements due to the heat generated by radioactive decay of fission products. 
At a high temperature (around $1000^{\circ} \mathrm{C}$ ), the rate of the heat generation due to oxidation of zirconium in the steam atmosphere may exceed that of radioactive decay, leading to fast uncontrolled temperature growth. As oxidation of zirconium is accompanied by free hydrogen release, the danger of hydrogen explosion is very high. Analysing 50 years of experience with nuclear energy, it can be concluded that such events happen rarely (Chernobyl - 1986, Fukushima Daiichi - 2011). However, when it happens, it seriously undermines trust of public opinion to the safety of nuclear power. Additionally, costs of restoration of damages made to reactor structure and environment are usually very high.

However it is not questioned that nuclear energy based plants are able to produce electrical energy in a free of carbon emission manner on a massive scale for the long time reaching 60 years or more. As an anthropogenic emission of carbon dioxide due to the application of fossil fuels for electricity generation is now considering as the biggest danger for the humanity, carefully designed and properly managed the nuclear power becomes very attractive replacement for it. It is worth to mention that new concepts of nuclear reactors elaborated in the framework of Generation IV Forum (fast reactors, high-temperature reactors, molten salt reactors) and recently developed proposition of fully ceramic microencapsulated (FCM) fuels for light-water reactor (LWR), while implemented, may essentially change the way fissile materials are utilized $[2,3]$. The increase in nuclear safety, cost-efficiency, reduction in wastes generated and resistance to diversion of nuclear materials are expected. Moreover, the generation of high-temperature heat enabling important chemical processes like water splitting would be possible with high-temperature reactors.

Soon, after the Fukushima accident, the nuclear international community focussed their interests on the development of nuclear fuel elements that will be resistant to such events. The concept of accident tolerant fuels (ATF) has been developed for this purpose and is now actively pursuit [4-16]. For this purpose, high-performance materials are required, which are less oxidizable in water steam environment, able to withstand high pressure inside the fuel tube to prevent ballooning in the absence of cooling water and preserve their mechanical properties under neutron irradiation. Additional complexity arises from the requirement that any change made to fuel elements should not disturb substantially neutron fluxes [17].

Different concepts were proposed for ATF. The most revolutionary one was based on replacing zirconium alloys with composites of silicon carbide. Another one was applying external oxidation resistant coating to the external surface of zirconium alloy tube. As on the way to introducing the new type fuel to the market the extensive tests are required fulfilling the existing regulations the little bit conservative concept of external coatings seems to have potential to be implemented in shorter time. The results of the research works published on this subject in open literature by the end of 2016 have been recently reviewed [18].
The leading companies from the nuclear sector are actively working on ATF implementation. According to commonly available data, the following projects are going on:

- application of silicon carbide composites as claddings for either current fuel or uranium silicide $\mathrm{U}_{3} \mathrm{Si}_{2}$ fuel (Westinghouse),

- application of zirconium alloy cladding coated with external chromium layer for uranium oxide fuel (dotted with small admixture of chromia (AREVA)) and

- ferritic/martensitic steel alloy claddings (e.g. $\mathrm{Fe}-\mathrm{Cr}-\mathrm{Al}$ ) and conventional uranium oxide fuel.

Recently, the renewed interest to nuclear power has been observed in Poland. The strategic research programme called "Technologies supporting development of safe nuclear power engineering" was established in a response to the expected nuclear power engineering introduction to Poland. Laboratory of Materials Research (INCT, Warsaw) joined this programme focusing their research works on zirconium oxidation mechanisms in normal working conditions and emergency cases as well as countermeasures that would help to mitigate catastrophic oxidation of zirconium in the case of LOCA. The technique of high-intensity pulsed ion-plasma beam treatment has been applied for the modification of the surface layer of zirconium. Using this method, the melting of the surface layer and doping with eroded metallic electrode materials such as Y, $\mathrm{Cr}$ and $\mathrm{Al}$ into the melted surface layer was possible. However, the concentration of doped elements was usually at the level of few percent that was not high enough for creation of protective oxide laver on the surface of the fuel rod in the case of temperature evolution. Good results in autoclave tests and in the oxidation test in air at a high temperature were obtained in the case of chromium layer of $3.5 \mu \mathrm{m}$ deposited by arc plasma discharge [19]. Based on this experience, we finally switched to physical deposition methods and selected zirconium silicides as possible protective coatings.

Different methods of coating deposition are known, such as chemical vapour deposition (CVD), physical vapour deposition (PVD), wet chemistry methods, thermal spray and gas dynamic cold spray. Magnetron sputtering, a kind of PVD process, based on deposition on the substrate of atoms ejected from the target by the action of energetic argon ion beam bombardment has some important advantages [17]. The most important of them are wide range of possible coating synthesis by deposition from one or more independent targets, uniform coating thickness, high purity of coatings and possibility of substrate surface cleaning via plasma prior to a deposition.

There are few reasons for the coating material choice. At first, zirconium and silicon are preferred over chromium due to the lower cross-sections for thermal neutron absorption in comparison to those of the chromium. Another ones are related to material properties of silicides, particularly to their high melting point, resistance to oxidation and similarity of liner thermal expansion coefficients to that of zirconium alloys. 


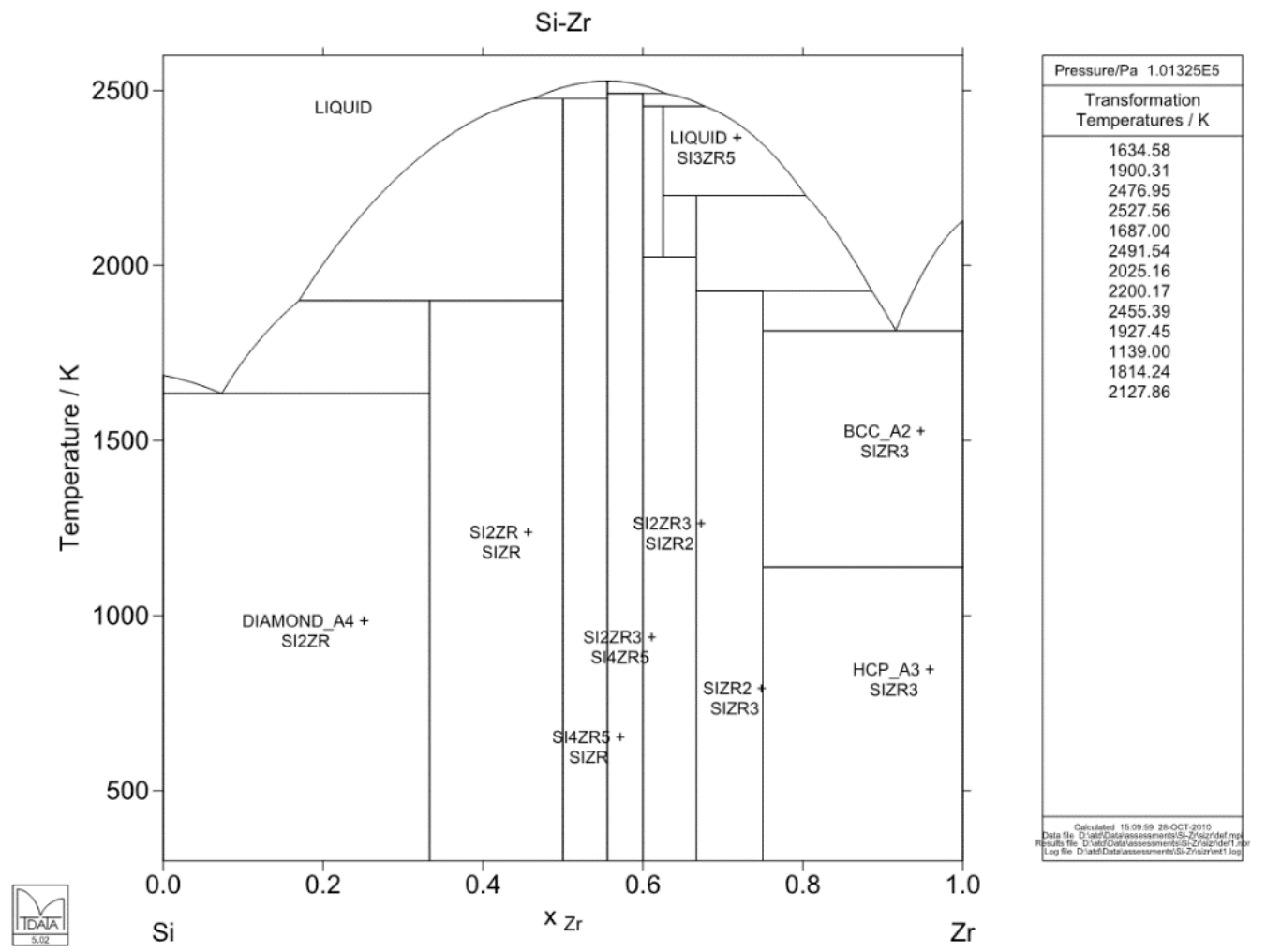

Fig. 1. The zirconium-silicon phase diagram.

Generally, zirconium silicide and zirconium silicate are known for good oxidation resistance in high-temperature conditions and for this reason are considered for application as environmental barrier coatings for high-temperature gas-turbine components. Only recently, they were started to be explored for application as corrosion protective coatings for nuclear fuel elements [20,21]. A review of existing literature and analysis of thermodynamic data indicate that silicon-based coatings may offer excellent prospects in this field [22-24]. Particularly, they may provide a more protective barrier than the native $\mathrm{ZrO}_{2}$ films formed on alloy cladding during routine nuclear plant operations and an exceptional protective barrier during high-temperature accident scenarios. A phase diagram of the Zr-Si system presented in Fig. 1 clearly shows existence of intermetallic compounds with different $\mathrm{Zr} / \mathrm{Si}$ ratios and stability regions. For example, $\mathrm{ZrSi}_{2}$ is stable up to $1620^{\circ} \mathrm{C}$ and $\mathrm{ZrSi}$ is stable up to $2210^{\circ} \mathrm{C}$. Temperature range of stability for zirconium $\left(\mathrm{ZrSiO}_{4}\right)$ extends to $1673^{\circ} \mathrm{C}$, where it thermally decomposes by solid state reaction giving $\mathrm{ZrO}_{2}$ and $\mathrm{SiO}_{2}$ [24].

Both zirconium and silicon readily form their respective oxides at high temperatures. According to the Ellingham diagram, the enthalpy of $\mathrm{ZrO}_{2}$ formation is higher than the enthalpy of silicon dioxide formation, and zirconium dioxide should be formed preferentially according to thermodynamic laws. However, kinetic factors also need to be taken into account. In the course of zirconium silicide oxidation, depletion of zirconium leads to increase in silicon activity and formation of silicon oxide. As the results $\mathrm{ZrO}_{2}$ or $\mathrm{SiO}_{2}$ or even $\mathrm{ZrSiO}_{4}$ may form depending on the stoichiometry of the $\mathrm{Zr}$-silicide. Moreover, in the case of $\mathrm{ZrSi}_{2}$ layer, depletion of silicon should lead to the formation of $\mathrm{ZrSi}$ possessing a higher melting temperature. Thus, it seems that zirconium silicide coatings with stoichiometry of $\mathrm{ZrSi}_{2}$ offer good prospects for the application as a protective layer for oxidation at high-temperature regions. To check this hypothesis, relevant studies have been undertaken.

\section{Experimental}

The multisource plasma magnetron sputtering developed in the Institute for Sustainable Technologies (IST, Radom) has been used for deposition of coatings. The system containing three magnetron plasma sources, three power and control systems, is dedicated for non-reactive magnetron synthesis of layers of composite materials. The commercially available zirconium alloy $\mathrm{Zr} 705$ grade $(\mathrm{Fe}-0.53 \%$, $\mathrm{Nb}-1.30 \%$, Hf $-1.91 \%, \mathrm{Zr}-96.14 \%$ ) supplied by Stanford Advanced Materials has been used for the sample preparation.

Slices of $5 \mathrm{~mm}$ in thickness were cut from the rod of $25.4 \mathrm{~mm}$ in diameter. The samples were polished with sand papers and cleaned by ultrasound bath. Furthermore, before coating deposition, their surfaces were etched in low-pressure glow discharge in argon gas. Zr-Si coatings were sputter deposited to a nominal thickness of about $3 \mu \mathrm{m}$ by the DC magnetron sputtering technique from a pure $\mathrm{Zr}$ and Si target and $\mathrm{ZrSi}_{2}$ sintered target with a diameter of $100 \mathrm{~mm}$ and a thickness of $8 \mathrm{~mm}$, adhesively bonded 
on a copper washer. Before deposition, the chamber was evacuated to $3 \times 10^{-3} \mathrm{~Pa}$ and the samples were heated up to about $300^{\circ} \mathrm{C}$. The working pressure during deposition was $0.5 \mathrm{~Pa}$, and the distance from the samples to the plasma source was $150 \mathrm{~mm}$. During the process, the temperature was constantly monitored using a pyrometric temperature measurement system. The negative bias of substrate was $-100 \mathrm{~V}$. The power applied to the $\mathrm{ZrSi}_{2}$ target was equal to $600 \mathrm{~W}$ maximum in the case of deposition from single $\mathrm{ZrSi}_{2}$ target. In the case of deposition from two independent targets, the power applied to the Si target amounted to $400 \mathrm{~W}$ and that to the $\mathrm{Zr}$ target amounted to $200 \mathrm{~W}$. The typical time of deposition of coatings was equal to 150 minutes.

Two series of samples were prepared using different combinations of targets. The first one was prepared using two independent zirconium and silicon targets. This allowed for the synthesis of coatings with different stoichiometries by changing relative sputtering rates of the targets. The second series were prepared using one target made of $\mathrm{ZrSi}_{2}$ compound.

The as-deposited samples were amorphous as was confirmed by X-ray diffraction studies. For the development of crystallinity, thermal treatment in neutral gas atmosphere of flowing argon in the tube furnace was necessary.

For the oxidation resistance determination of coatings, two types of tests were performed. One of them aimed at the oxidation kinetics determination and another one at performance determination in the case of simulated accident conditions. For the oxidation kinetics study, weight increase of the sample was determined after their oxidation in air at a temperature of $700^{\circ} \mathrm{C}$. The sample coated on both faces was periodically placed into the warmed up furnace and taken out after one hour warming up period up to 5 times maximum. After cooling on air, the weight of the sample was determined using a precision balance. The weight increment data were fitted to the power function. Independently, the four one-side coated samples were placed into the furnace warmed to $700^{\circ} \mathrm{C}$ and were taken out one by one in one hour interval for the SEM studies on morphologies and thicknesses evolution of coated layer in the course of oxidation.

For the determination of performance in the case of uncontrolled temperature growth in the case of

Table 1. Mass gain due to the oxidation in air at $700^{\circ} \mathrm{C}$

\begin{tabular}{cccc}
\hline $\begin{array}{c}\text { Time } \\
{[\mathrm{h}]}\end{array}$ & $\begin{array}{c}\text { Zr alloy, raw } \\
{[\mathrm{g}]}\end{array}$ & $\begin{array}{c}\text { Coated from } \\
\mathrm{ZrSi}_{2} \text { target } \\
{[\mathrm{g}]}\end{array}$ & $\begin{array}{c}\text { Coated from Zr } \\
\text { and Si targets } \\
{[\mathrm{g}]}\end{array}$ \\
\hline 1 & 0.0264 & 0.0096 & 0.0072 \\
2 & 0.0325 & 0.0134 & 0.0088 \\
3 & 0.0383 & 0.0156 & 0.0126 \\
4 & 0.0472 & 0.0195 & 0.0143 \\
5 & 0.0585 & 0.0241 & 0.0184 \\
\hline
\end{tabular}

LOCA condition, the one-side coated samples were placed inside the furnace warmed up to $1100^{\circ} \mathrm{C}$ for 1000 seconds in atmospheric air and after that taken out and dropped immediately into the water.

On each step of research, the scanning electron microscope - SEM (Ultra Plus, Zeiss), X-ray diffractometer - XRD (D8 Advance, Bruker) and energy dispersive X-ray spectroscopy - EDX (Quantax, Bruker) methods were applied for the morphological, structural and elemental composition studies.

\section{Results}

The results of weigh increase resulting from the oxidation in air at temperature of $700^{\circ} \mathrm{C}$ are given in Table 1 for two types of coated samples and for the raw sample. The data were fitted to the power function of the form

$$
\begin{aligned}
& w^{k}=\alpha \cdot t \\
& \text { or the logarithmic form } \\
& \qquad \log (w)=1 / k * \log (t)+\log (\alpha) / k
\end{aligned}
$$

where $w$ is the mass gain and $t$ the time.

The results of linear regression fitting are presented in Table 2.

The analysis of the data obtained clearly shows smaller mass gain in the case of coated samples. For the samples coated from two targets, the mass gain for the 5 -hour oxidation in air at $700^{\circ} \mathrm{C}$ is 3.17 times smaller than that in the case of the raw sample. Analysis of the regression data confirms the protective nature of coatings. The obtained values of exponential factor $k$ equal to 1.73 (in the case of deposition from two targets) and 1.83 (in the case of deposition from one target) are slightly smaller than the ideal value of 2 , corresponding to the case when diffusion of oxygen through the layer is the main responsible mechanism for the mass gain during oxidation. It cannot be excluded that small porosity exists in the coatings directly related to the columnar-like microstructure of coatings obtained by magnetron sputtering. It is worth to mention that the coatings from two targets exhibit smaller values of mass increase with the time of oxidation. It was also found that the samples prepared from two targets after treatment at $700^{\circ} \mathrm{C}$ in atmospheric air for 4 hours exhibit smooth surface, free of visible cracks, while in the case of coatings prepared with application of $\mathrm{ZrSi}_{2}$ compound target, the network of cracks was clearly visible.

Experiments performed at a higher temperature of $1100^{\circ} \mathrm{C}$ with fast cooling in water show again the better performance of the coated samples. The mass gain for the uncoated sample was equal to $0.3039 \mathrm{~g}$, while for the sample coated from two targets, it was $0.2216 \mathrm{~g}$ and for the sample coated from one compound target, it was $0.2159 \mathrm{~g}$.

It was mentioned already that as-deposited samples were amorphous. The thermal treatment of the

Table 2. The functional form of linear regression fitting to the mass gain due to the oxidation in air at $700^{\circ} \mathrm{C}$

\begin{tabular}{ll}
\hline $\mathrm{Zr}$ alloy, raw & $\log (w)=0.4738 * \log (t)-1.6505$ \\
Coated from $\mathrm{ZrSi}_{2}$ target & $\log (w)=0.5474 * \log (t)-2.0327$ \\
Coated from $\mathrm{Zr}$ and Si targets & $\log (w)=0.5768 * \log (t)-2.1754$ \\
\hline
\end{tabular}




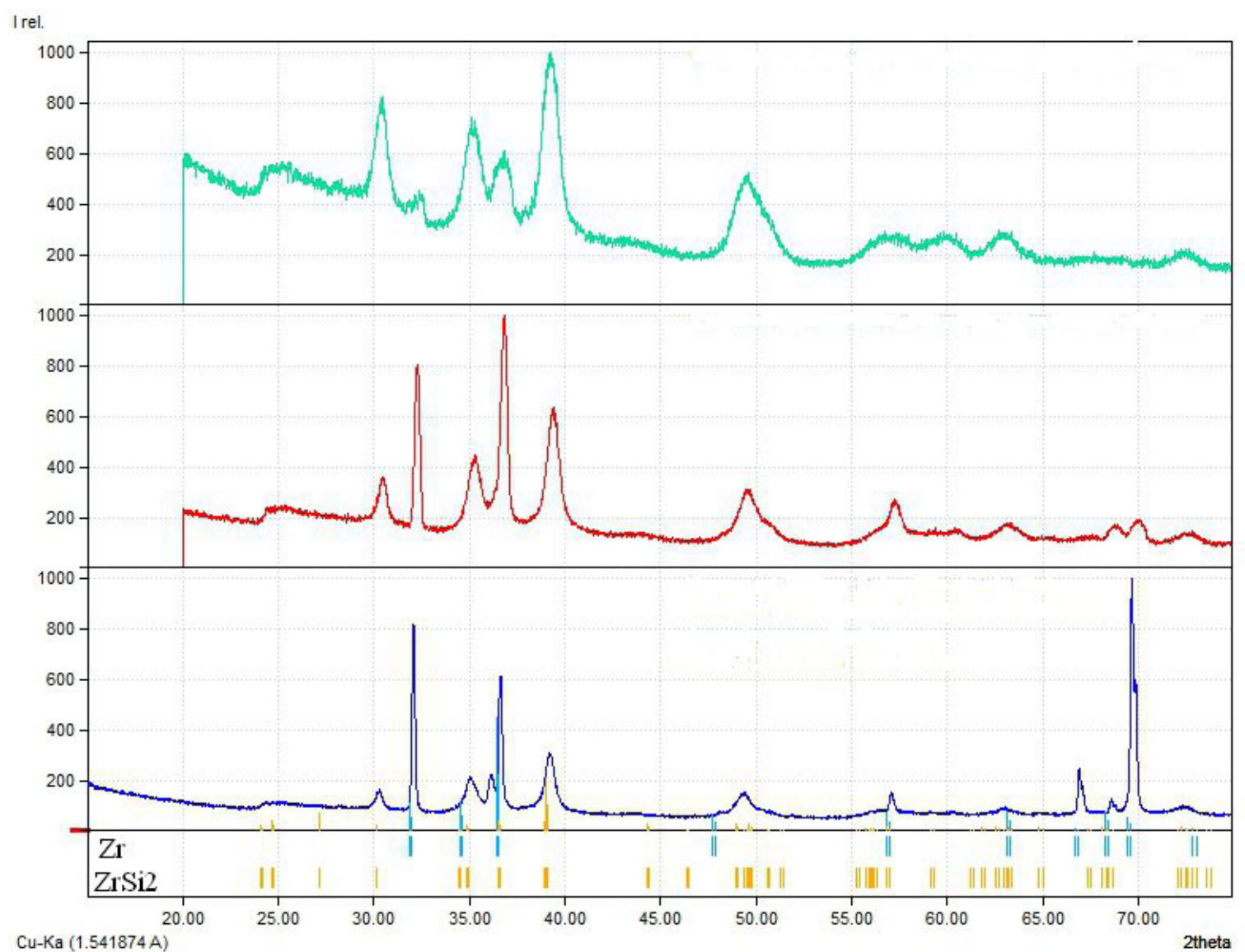

Fig. 2. The XRD spectra of coating deposited from the two independent targets (Zr, Si) after thermal treatment at a temperature of $800^{\circ} \mathrm{C}$ in flowing argon atmosphere in normal geometry (lower) at glancing angles of $10^{\circ}$ (middle) and $5^{\circ}$ (upper).

samples in the furnace at flowing argon atmosphere enabled for the development of crystallinity. This was confirmed by XRD measurements presented in Fig. 2, showing the spectra measured at normal Bragg-Brentano geometry and at glancing angles of $5^{\circ}$ and $10^{\circ}$.

It is seen that in the case of normal diffraction geometry, the zirconium substrate reflection is dominated in the spectrum (marked with blue markers), while in the other two cases, especially at a glancing angle of $5^{\circ}$, the reflections belonging to the $\mathrm{ZrSi}_{2}$ phase are clearly visible (marked with yellow marks). The Rietveld refinement of the XRD spectra based on the model of two contributing phases $\mathrm{Zr}$ and $\mathrm{ZrSi}_{2}$ converged successfully, confirming the validity of the model.

The SEM studies of cross-sections of thermally treated coated samples allow us for making interesting observation of the morphology of coatings. After treatment in non-oxidizing argon atmosphere, we observed the formation of layered structure inside the coating. Three distinct layers can be distinguished as is shown in Fig. 3. For each of the layer, different elemental contents of zirconium, silicon and oxygen were found using the EDX method.

Starting from the outer region, we can observe the following:

- The thin external layer containing $\mathrm{Zr}$, Si and O elements. The presence of monoclinic $\mathrm{ZrO}_{2}$ has been confirmed already by XRD spectra, and this phase is probably present mainly here. The structural form of $\mathrm{Si}$ is at present unknown. The XRD diffraction does not give any evidence for the presence of crystalline forms. The presence of amorphous silicon oxides is possible and needs to be confirmed.

- The middle layer with near $\mathrm{ZrSi}_{2}$ stoichiometry. The XRD studies confirm the presence of crystalline $\mathrm{ZrSi}_{2}$.

- The wider, near to the bulk Zr alloy layer with stoichiometry $\mathrm{ZrSi}$.

The presence of oxygen in the near-surface layer is the result of oxidation due to some admixture of this element still present in our flowing argon tube furnace.

The similar three-layer structure can be observed in the case of samples oxidized in air at $700^{\circ} \mathrm{C}$ for 3 hours, presented in Fig. 4. In this case however, contradictory to the case presented in Fig. 4, step-like region of high concentration of silicon can be seen at the surface and this can be attributed to the presence of silicon oxide phase.

The experimental observation of in situ formation of smooth, parallel layers in the coatings initially containing mixture of zirconium and silicon during thermal treatment was not described earlier. It seems to be worth to investigate further structural properties of formed layers. The formation of $\mathrm{ZrSi}$ phase near the surface of bulk zirconium alloy would allow for extending the temperature range where zirconium silicides may be protective against oxidation. 

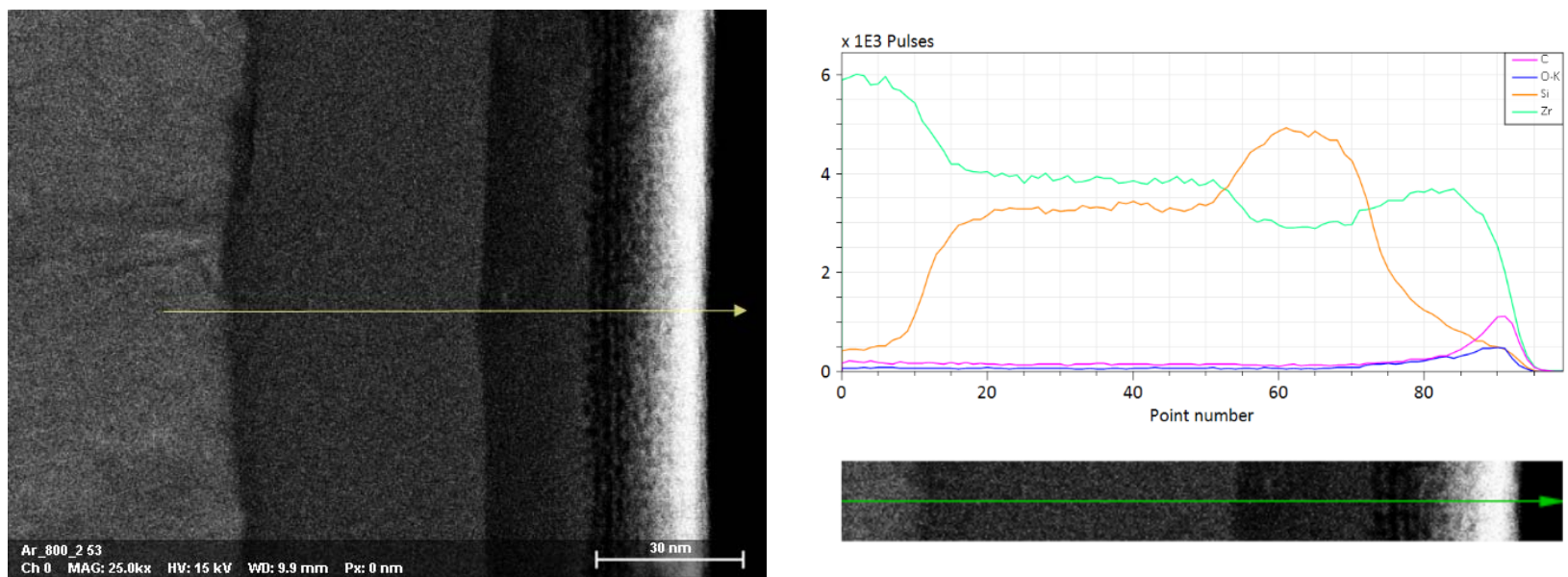

Fig. 3. The SEM view of cross-section of coating made from the two independent targets ( $\mathrm{Zr}, \mathrm{Si}$ ) (left) and elemental distribution across the coating after treatment in flowing argon at a temperature of $900^{\circ} \mathrm{C}$ for 4 hours.
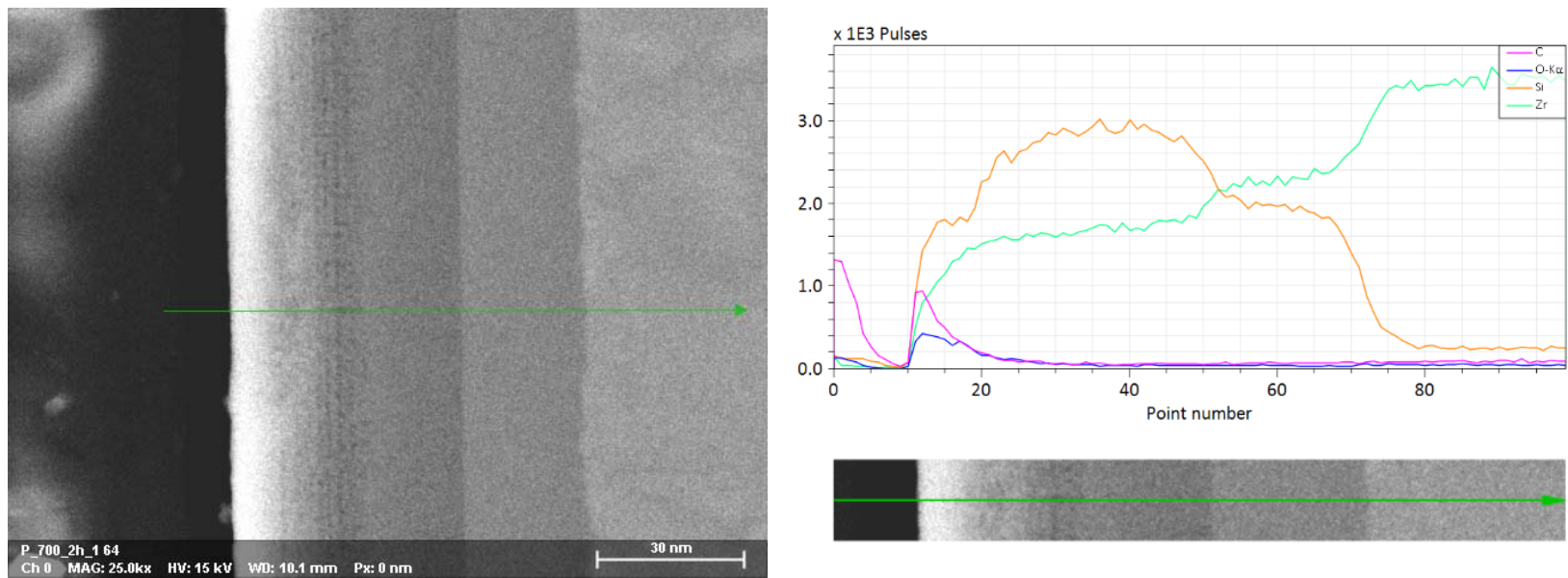

Fig. 4. The SEM cross-section view and elemental content distribution of the sample coated from two independent targets $(\mathrm{Zr}, \mathrm{Si})$ after oxidation in air at temperature of $700^{\circ} \mathrm{C}$ for 3 hours.

\section{Conclusions}

The safety of the nuclear installation in the case of beyond design accidents strongly depends on materials utilized. To avoid in the future catastrophic accident like that in Fukushima, there is necessity to develop high-performance materials that can withstand severe oxidation conditions present in the case of accidents. In the studies presented in this paper, the zirconium silicide material was proposed as a protective coating for the zirconium alloy fuel tubes. Preliminary studies performed confirmed protective character of this coating at the temperature ranges investigated. The method of coating deposition from two independent targets allows for the preparation of thin coatings in the range of few micrometres with different stoichiometries. It seems that these variants are preferable over deposition using one target with definite stoichiometric composition as usually stoichiometry is not preserved during deposition. Moreover, no cracks were observed in the case of deposition using two elemental targets. The interesting observation of the in situ formation of layered structure with different compositions inside coatings during thermal treatment in argon and air could be utilized for the development of coatings protective against oxidation at high temperatures.
Acknowledgments. The financial support from Ministry of Science and Higher Education grant under decision $3787 / Z$ IBJ Dubna/2017/0 is gratefully acknowledged.

\section{References}

1. IAEA. (2017). Nuclear technology review 2017. Vienna: International Atomic Energy Agency. (IAEA/ NTR/2017).

2. Pioro, I. (2016). Handbook on generation IV nuclear reactors. Waltham, MA: Elsevier Ltd.

3. Terrani, K. T., Kiggans, J. O., Silva, C. M., Shih, D., Katoh, Y., \& Snead, L. L. (2015). Progress on matrix SiC processing and properties for fully ceramic microencapsulated fuel form. J. Nucl. Mater., 457, 9-17. DOI: 10.1016/j.jnucmat.2014.10.034.

4. IAEA. (2014). Accident tolerant fuel concepts. Proceeding of the technical meeting held at the Oak Ridge National Laboratories, USA, 13-16 October 2014. Vienna: International Atomic Energy Agency. (IAEA-TECDOC-1797).

5. Zinkle, S. J., Terrani, K. A., Gehin, J. C., Ott, L. J., \& Snead, L. L. (2014). Accident tolerant fuels. A perspective. J. Nucl. Mater., 448, 374-379.

6. Morell, P. (2015). Phase 1A Final Report for the AREVA Team Enhanced Accident Tolerant Fuels 
Concepts. (Report DOE-AFS-0000567). DOI: 10.2172/1172983.

7. Pint, B. A., Terrani, K. A., Yamamoto, Y., \& Snead, L. L. (2015). Material selection for accident tolerant fuel cladding. Metall. Mater. Trans. E, 2(3), 190-196. DOI: $10.1007 / \mathrm{s} 40553-015-0056-7$.

8. Kim, H., Yang, J., Kim, W., \& Koo, Y. (2016). Development status of accident-tolerant fuel for light water reactors in Korea. Nucl. Eng. Technol., 48, 1-15. https://doi.org/10.1016/j.net.2015.11.011.

9. Koo, Y., Yang, J., Park, J., Kim, K., Kim, H., Kim, D., Jung, Y., \& Song, K. (2014). KAERI's development of LWR accident-tolerant fuel. Nucl. Technol., 186(2), 295-304. http://dx.doi.org/10.13182/NT13-89.

10. Barrett, K., Bragg-Sitton, S., \& Galicki, D. (2012). Advanced LWR nuclear fuel cladding system development trade-off study. Idaho National Laboratory. (INL/EXT-12-27090).

11. Kurata, M. (2016). Research and development methodology for practical use of accident tolerant fuel in light water reactors. Nucl. Eng. Technol., 48, 26-32. DOI: https://doi.org/10.1016/j.net.2015.12.004.

12. Yueh, K., \& Terrani, K. A. (2014). Silicon carbide composite for light water reactor fuel assembly applications. J. Nucl. Mater., 448, 380-388. http://dx.doi. org/10.1016/j.jnucmat.2013.12.004.

13. Idarraga-Trujillo, I., Le Flem, M., Brachet, J., Le Saux, M., Hamon, D., Mueller, S., Vanderberghe, V., Tupin, M., Papin, E., Monsierot, E., Billard, A., \& Schuster, F. (2013). Assessment at CEA of coated nuclear fuel cladding for LWRs with increased margins in LOCA and beyond LOCA conditions. In Top Fuel 2013 September 15-19, 2013, Charlotte, NC, USA (pp. 860-867).

14. Rebak, R., Terrani, K., Gassmann, W. P., \& Williams, J. B. (2017). Improving nuclear Power plant safety with FeCrAl alloy fuel cladding. MRS Adv., 2(21/22), 1217-1224. https://doi.org/10.1557/adv.2017.5.

15. Terrani, A. K., Pint, B. A., Kim, Y. J., Unocic, K. A., Silva, C. M., Meyer III, H. M., \& Rebak, R. B. (2016). Uniform corrosion of FeCrAl alloys in LWR coolant environments. J. Nucl. Mater., 479, 36-47. http:// dx.doi.org/10.1016/j.jnucmat.2016.06.047.

16. Yamamoto, Y., Pint, B. A., Terrani, K. A., Field, K. G., Yang, Y., \& Snead, L. L. (2015). Development and property evaluation of nuclear grade wrought $\mathrm{FeCrAl}$ fuel cladding for light water reactors. J. Nucl.
Mater., 467, 703-716. http://dx.doi.org/10.1016/j. jnucmat.2015.10.019.

17. Younker, M., \& Fratoni, M. (2016) Neutronic evaluation of coating and cladding materials for accident tolerant fuels. Prog. Nucl. Energy, 88, 10-18. http:// dx.doi.org/10.1016/j.pnucene.2015.11.006.

18. Tang, C., Stueber, M., Seifert, H. J., \& Steinbruck, M. (2017). Protective coatings on zirconium-based alloys as accident-tolerant fuels (ATF) claddings. Corros. Rev., 35(3), 141-165. DOI: 10.1515/corrrev-2017-0010.

19. Starosta, W., Barlak, M., Buczkowski, M., Kosińska, A., Sartowska, B., Waliś, L., \& Janiak, T. (2015). Analiza mechanizmów tworzenia się oraz właściwości warstw tlenkowych powstających w wyniku rozkładu wody na powierzchni koszulek cyrkonowych oraz zbadanie wpływu modyfikacji struktury warstwy wierzchniej koszulek na procesy generacji wodoru. In J. Michalik, \& R. Kocia (Eds.). Analiza procesów generacji wodoru w reaktorze jadrowym $w$ trakcie normalnej eksploatacji i w sytuacjach awaryjnych $z$ propozycjami działań na rzecz podniesienia poziomu bezpieczeństwa jądrowego (pp. 55-72). Warszawa: Institute of Nuclear Chemistry and Technology.

20. Mariani, R., Medvedev, P., Porter, D. L., Hayes, S. L., Cole, J. I., \& Bai, X. (2013). Novel accident-tolerant fuel meat and cladding. In Top Fuels, September 15-19, 2013, Charlotte, NC, USA (pp. 763-770).

21. Yeom, H., Maier, B., Mariani, R., Bai, D., Fronek, S., Xu, P., \& Sridharan, K. (2017). Magnetron sputter deposition of zirconium-silicide coating for mitigating high temperature oxidation of zirconium-alloy. Surf. Coat. Technol., 316, 30-38. http://dx.doi. org/10.1016/j.surfcoat.2017.03.018.

22. Kaiser, A., Lobert, M., \& Telle, R. (2008). Thermal stability of zircon $\left(\mathrm{ZrSiO}_{4}\right)$. J. Eur. Ceram. Soc., 28, 2199-2211. DOI: 10.1016/j.jeurceramsoc.2007.12.040.

23. Lavrenko, V. A., Shemet, V. Zh., \& Goncharuk, A. V. (1985). Studies on mechanism of high-temperature oxidation of molybdenium, tungsten and zirconium disilicides by differential thermal analysis. Thermochim. Acta , 93, 501-504. https://doi.org/10.1016/00406031(85)85126-1.

24. Ueno, S., Ogji, T., \& Lin, H. T. (2007). Corrosion and recession behavior of zircon in water vapor environment at high temperature. Corros. Sci., 49(3), 1162-1171. https://doi.org/10.1016/j.corsci.2006.08.013. 